\title{
Bourdieu and interprofessional education: what's the relevance?
}

\author{
Marjorie Bonello, Jon Wright, Jane Morris \& Gaynor Sadlo \\ Faculty of Health Sciences, University of Malta, Msida, Malta; \\ School of Health Sciences, University of Brighton, Eastbourne, UK; \\ NAEP, Brighton, UK; \\ Department of Rehabilitation, Charles University, Prague, Czech Republic
}

\begin{abstract}
Interprofessional education (IPE) is perceived to be one strategy to reduce professional compartmentalisation and improve collaborative practices. The unequal power relationsexisting between the various professions who need to collaborate for IPE remains largely unexamined and it is only in recent years that sociological theories have been employed within the interprofessional field. This paper uses selected findings from an exploratory case study into IPE conducted at the University of Malta and then examines these findings from a Bourdieusian perspective. The first part of this paper introduces the breath of theoretical perspectives employed for IPE and then goes on to provide an overview of Bourdieu's theories of social practices. The second part outlines the context of this case study and presents selected findings. The third section discusses how these findings were examined using Bourdieu's concepts helping us demystify the various ways in which health care professions worked and interacted, and how this all made sense within a wider societal context. It also highlights the relevance of taking into account Bourdieu's concepts during the development of IPE.
\end{abstract}

Keywords

Bourdieu's concepts of field; habitus; capital and doxa;

interprofessional education; power; conflict

\section{Introduction}

The term interprofessional denotes a group of professionals from different disciplines working together. Within an interprofessional collaborative environment each professional provides his/her knowledge, skills, and attitudes to augment and support the contributions of others (Hall and Weaver 2001). One of the strategies developed to facilitate this process is interprofessional education (IPE) which is perceived to cultivate collaborate practices. These practices could be transferable to any professional group however for the purposes of this paper, IPE will be contextualised to the healthcare setting; the setting where the majority of IPE scholarship and research is located.

Despite strong imperatives for IPE worldwide (Frenk et al. 2010; WHO 2013, 2010) and limited but growing evidence regarding the benefits of IPE (Reeves et al. 2016), implementation remains problematic. IPE is complex in its definition, purpose and method (Cooper, Braye, and Geyer 2004) giving rise to professional, organisational, philosophical and sociological barriers (Chesters and Burley 2011; Hall and Weaver 2001; 
Harris 2006; Reeves, MacMillan, and Van Soeren 2010). This paper which focuses on professional and sociological barriers emerges from a case study analysis exploring the possibility of IPE at the Faculty of Health Sciences at the University of Malta. In seeking a fresh lens on how to interpret the data, the authors applied Bourdieu's theoretical constructs for critically examining and discussing some of the findings.

\section{Theoretical perspectives on IPE}

The use of explicit theory underpinning IPE encourages 'systematic, disciplined and critical thinking' (Barr et al. 2005, 120). Early published accounts of IPE initiatives were largely under theorised (Reeves and Hean 2013) however in recent years this has changed as attested by a number of published works outlining theories, which are utilised or could be utilised for informing IPE (Barr 2013; Hean, Craddock, and O’Halloran 2009; Reeves et al. 2007; Reeves and Hean 2013). These theories originate from various academic disciplines ranging from learning theories, psychodynamic theories, social psychology, sociology, systems theories and organisational theories (Reeves et al. 2007). ${ }^{1}$ Some theories address the individual learner (such as adult learning theories), others address group collaboration (such as communities of practice), and others address the entire system (such as complexity and organisational theories) (Barr et al. 2005).

Under the sociological perspectives emerges Pierre Bourdieu's (1930-2002) theories whose work primarily concerns the dynamics of power in society and the diverse ways in which power is transferred and perpetuated (Bourdieu 1989). However, despite IPE being a field in which professions' embedded hierarchical, stereotypical and territorial behaviours and practices are deeply rooted in the socialisation processes and professionalisation discourses of health care professions and which could run counter to the philosophical idea of an egalitarian foundation on which IPE needs to be built (Khalili, Hall, and DeLuca 2014), Bourdieu's perspectives and indeed sociological perspectives in general remain largely underutilised (Reeves and Hean 2013).

Almås (2007) is one of the few scholars who used Bourdieu's theory of education (Bourdieu 1989) to explore and understand the implementation process of a common core curriculum. Her findings revealed that such a common core curriculum was not sufficient to improve students' identities or professional habitus (personal disposition and professional identity); rather, what was central for a change in students' professional habitus was the interaction made possible during IPE. Hean et al. (2012) analysed Bourdieu's multidimensional concept of social capital and then went on to translate its significance into tangible curriculum opportunities for IPE. Paradis and Reeves (2013) also used a Bourdieusian theoretical framework to explore the growth and the changing nature of interprofessional research during 1970-2010; four decades in which the authors conceptualised interprofessional research as a field struggling for power and legitimacy thereby mirroring Bourdieu's conceptualisation of power struggles within the academic domain. The section to follow provides a brief overview of Bourdieu's theories through which selected findings from this case study are examined. 


\section{Bourdieu's key theories and concepts}

Bourdieu wrote prolifically about how educational institutes have contributed to societal inequality. He was drawn to the metaphor of social life as a game in the sense of a player's learning and understanding the rules of the game (Jenkins 2014). His pivotal concepts centre on the interrelated ideas of field, habitus, capital and doxa and he uses these concepts to analyse social relations and the forces that shape them. Bourdieu claims that all actions and practices in any sphere of human interaction within social arrangements are interest motivated, be it by material or symbolic gains. The social field becomes one in which people struggle for positions so as to augment their gains and accumulate resources (Navarro 2006).

For Bourdieu, the metaphor of the field always signifies a field of force, power and competition. A field is described as a configuration of positions comprising agents (individuals, groups of actors or institutions) contesting to maximise their position, usually with regard to resources, stakes and access (Bourdieu and Wacquant 1992). A field of practice represents an 'arena of struggle around production, accumulation, circulation and possession of goods, services, knowledge, or status and the competition amongst agents to monopolise distinct capital' (Navarro 2006, 18). A profession, from Bourdieu's perspective, constitutes a group of individuals placed within circumscribed areas of knowledge, each within their own historical contexts, different positions, dispositions and likely courses of action so as to assume positions of the dominant and dominated. These positions within the field are, in turn, determined by multiple sources of influences, such as habitus and capital (Bourdieu and Wacquant 1992).

Habitus, apart from family and early schooling experiences, is influenced by the socialisation process a trainee professional undergoes, giving rise to the particular cultural code and professional identity of a profession. It also creates a world view which is largely taken for granted and remains unquestioned; an acquired and ingrained disposition (conscious and/or unconscious). Habitus is also reinforced by educators who teach in ways that mirrors the dominant culture through methods accepted by this dominant culture. An example would be the way a professional within a given culture perceives himself and interacts with another professional, requiring the professional to attune himself so as to embody the rules, beliefs and habits of that particular profession.

Bourdieu's (1990) concept of habitus also refers to the 'way society becomes deposited in persons in the form of lasting dispositions, or trained capacities and structured propensities to think, feel and act in determinate ways' (316). Habitus is also the individual's features, viewpoints and dispositions with which an individual navigates the social world (Lynam et al. 2007), these being the basis of practices that develop through socialisation (which is highly influenced by schooling and education) and determine a wide range of dispositions, shaping and guiding the individual in society (Navarro 2006). This concept suggests that individuals develop and become themselves, so to speak, as a result of conscious and unconscious practices in the family context (product of history); and these dispositions are then transformed into secondary, tertiary or even further habitus as the individual journeys through different experiences and social institutions. The influence of context and environment imply that habitus is a social process (rather than personal), always changing according to new experiences (Navarro 2006). 
Bourdieu contends that individuals use and mobilise their resources so as to establish and sustain their position in the social order. These resources constitute Bourdieu's third concept, capital, which refers to resources that are useful for power and which can be used to control objects, persons and institutions. Bourdieu uses symbolic capital as an overarching concept and then differentiates between social, cultural and economic capital.

Symbolic capital refers to the social value given to certain things and is a form of capital that a group or a profession perceives as valuable (e.g. authority, prestige, titles and reputation); it is not really recognised in itself but depends on other people's perceptions that someone possesses those properties. Social capital refers to the socially advantageous position brought about by acquaintances and connections in networks of influence and memberships of family, social or political connections. Cultural capital, refers to the knowledge, skills, education and advantages that a person has and, in its institutionalised form, refers to credentials and qualifications that symbolise cultural competence and authority. Economic capital is the command over economic resources and other material values (Bourdieu 1986). Within Bourdieusian terms, professionalism is a 'a form of symbolic capital characteristic of a historically constructed field of power' recognising the dynamic nature and vulnerability of professional fields (Schinkel and Noordegraaf 2011, 85). This construction of professionalism is consistent with the sociological perspective supported by Larson (1977) and Freidson (1988a, 1988b, 1994) who argue that the creation of occupational groups, most notably the medical profession, was, in effect, the outcome of critical engineering by the professions in translating their special knowledge and skills into social mobility (higher status) and economic rewards (higher remuneration); a process akin to market closure securing economic and status rewards.

The ultimate stake in the social field is doxa which is the taken-for-granted rules in the field or a shared world view and could be a set of core values and discourses which would tend to be viewed as inherently true and necessary. However, even within this doxa, agents can occupy positions aimed at either conserving or transforming the structure or relations of forces in a field (Bourdieu 1990).

\section{Case study context}

Malta is located in the centre of the Mediterranean Sea and is one of the smallest and most densely populated countries in Europe. The Maltese public health care system is funded through taxation and national insurance and operates through public hospitals and health care centres. Similar to the international scenario, the local health system faces many challenges and in response there have been a number of health reforms. An example is the National Health Systems Strategy (Ministry for Health 2014) which espouses towards a client-centred and a collaborative approach of health care delivery. However, this strategy falls short in outlining how these collaborative approaches are to be fostered; the assumption and expectation from the policy makers is that health graduates would 'naturally' learn to work together.

To date, no local IPE initiative has ever been designed or implemented at the Faculty of Health Sciences, University of Malta. This faculty is responsible for the education and training of nursing, mental health nursing, midwifery, applied medical science, 
communication therapy, food studies and environmental health, occupational therapy, physiotherapy, podiatry and radiography. ${ }^{2}$ The programme of studies at this Faculty and across University at large are organised in traditional educational silos. The objective of this research study was to explore Faculty of Health Sciences academics' and other stakeholders' attitudes and perceptions of IPE with the possibility of developing and sustaining an undergraduate IPE initiative at the Faculty of Health Sciences, University of Malta.

\section{Methodology}

The study adopted a qualitative case study approach with the unit of analysis being 'the possibility of IPE at the Faculty of Health Sciences'. Case study methodology was well suited to understand the complexity and uniqueness of a bounded system, or in Bourdieusian's terms a field of practice, encompassing the contextual determinants (Simons 2009; Stake 1995). Data collection, which was carried out by the primary researcher, consisted of a purposive sample of sixty-four participants comprising of:

- Ten focus groups with resident academics ${ }^{3}$ representing the ten professions at the faculty (total number of participants was fifty-three). Through their synergistic potential, focus groups generated interpretative insights seldomly produced through individual interviewing (Kamberelis and Dimitriadis 2005). All resident academics from the ten Faculty of Health Sciences departments were invited to take part in homogenous focus groups exploring and debating IPE. The decision to conduct professional homogenous groups was taken by the primary researcher who with her insider knowledge of multiprofessional gatherings perceived that faculty members would feel more at ease to discuss interprofessional issues with their own professional colleagues.

- One focus group with six newly qualified health professionals ${ }^{4}$ who represented some of the professions which had finished their programme of studies in the previous year from the Faculty of Health Sciences and were working as registered health professionals within the national health service. This was a heterogeneous focus group because small numbers of qualifying professions were involved.

- Five one-to-one key informant interviews with stakeholders who were crucial to an IPE initiative ever being conceptualised or implemented at the faculty. Purposive sampling was used and five key informants holding high office from the health and higher education contexts were short-listed.

- .Documentary search so as to provide the historical and current contexts of the case and to cross validate information gathered from the primary data (Noor 2008).

This case study methodology was located within a relativist and interpretive perspective and thus ideal to examine the habitus of these participants in relation to their own profession, other professions, the organisation and other stakeholders as well as understanding of how this all fits in within the existing hierarchies. As advocated by Bourdieu (Bourdieu and Wacquant 1992), the primary researcher engaged in an intensive reflexive process all 
throughout the study critiquing her own field of practice, her habitus and capital and how these could affect and potentially bias her interpretation of the social world.

The study was approved by the Faculty Research Ethics and Governance Committee, University of Brighton and the University Research Ethics Committee, University of Malta.

\section{Questioning route}

An open-ended, non-leading questioning route based on the research objective was developed and pilot tested. This questioning route explored perceptions and understandings of IPE (including potential barriers and enhancers) held by the different participant groups.

\section{Data analysis}

The eleven focus groups and five one-to-one interviews were audio-recorded and transcribed by the primary researcher. The multi-phased and interpretative data analysis process was carried out following a 'Framework' analysis approach (Ritchie and Spencer 1994) supported by QSR NVivo 10. During this process, we were cognisant of Bourdieu's theoretical concepts, for example participants' attitudes and dispositions and the ways in which they engaged in certain practices and hierarchical behaviours. We were also aware of Bourdieu's notion of capital and the different forms of value that participants attached to their professions. Trustworthiness of data was achieved by employing credibility, transferability, dependability and confirmability which included prolonged engagement in the field, triangulation, member checking, dense descriptions, audit trail and reflexivity (Lincoln and Guba 1985). Confirmability of emerging themes was also supported by the two independent colleagues.

\section{Findings}

The findings yielded rich insights into participants' perceptions of IPE. In the main, they identified a multiplicity of factors that would pose barriers to its enactment in practice. On a symbolic level, participants were particularly concerned that IPE would pose a threat to their professional identities and to the maintenance of boundaries that define the conceptual territories of the various professions. Participants also pointed to traits and behaviours they perceived as endemic in the professional cultures that would conflict with the enactment of IPE. These barriers were encapsulated in a number of themes which collectively represented the dominant issues and concerns voiced by the participants. This paper will report on three particular themes: medical model reigns supreme, hegemonies and territoriality at the faculty and realities of teamwork because these themes encapsulated the ideas of power, conflict and dominant interests associated with the possibility of IPE at the Faculty of Health Sciences. They were also the themes which resonated with Bourdieu's fields of practice in which players occupy different positions according to their resources. Extracts from the focus groups and key informant interviews are presented to illustrate and provide evidence for the themes. The profession in which the academic tutors and newly qualified health professions appertained will not be disclosed due to anonymity issues; instead participants will simply be 
identified by their participant group and number. In the case of the key informants their excerpts will not be enumerated due to the possibility of identification by a local readership.

\section{Medical model reigns supreme}

This theme reflected participants' sense of dissatisfaction with medical dominance in the health and academic sectors, as well as in wider society; a dynamic they perceived as incompatible with IPE.

A major impediment to IPE, is the predominance of a medical model mentality and outlook (Academic tutor, 30).

Participants across all groups contended that, although great strides were made in elevating the scholarship of their professions reflecting international trends in health care education, their professional status was sabotaged and dominated by the medics, resulting in a 'tug of war' between differing approaches within health care:

It is not just the thing between us and them, it's a whole different mentality. Over here at the Faculty, the programme is for our students to go into holistic practice and evidence-based practice, but within the clinical setting it's a different drive, a different attitude, a completely different attitude. So basically, it's not just meeting up, explaining our position, it's literally a tug-ofwar, I'd say, between two different extremes (Academic tutor, 51).

Participants brought up the powers of the hidden curriculum and clinical realities when they spoke about the lack of alignment between what is espoused in the classroom and what happens on practice placements. For example, Academic 18 spoke about the time when:

I was teaching them for a whole semester in one direction. And I sent them for one clinical visit into the hospital to see how it's practised and one year later the only thing they remembered was not what was taught but what was seen ... and it contaminated a whole group of people, a whole semester of work, a whole semester of trying to ingrain a certain philosophy (Academic tutor, 18).

When we go to clinical practice, we feel we are not seen ... it is the doctors who run the show (Newly qualified professional, 1)

Participants perceived that wider society supported the medical model which meant that frequently their expertise was generally undervalued and was unrecognised.

In the field, even if you work in private practice for example, even a simple receptionist will treat you differently to the way they treat a doctor, it's on that level and it really hurts, this is lower down, you know what I mean ... even a question of a room, if it's a choice between a doctor and another professional, who will be given the room? ... the doctor of course (Academic tutor, 25).

This medical dominance permeating the local health services was perceived to have a negative impact on students' developing sense of autonomy, competence and worth.

Professional identity, I think our students come with a lot, but then, unfortunately, when they come here and they visit the clinical practice, it kind of dies down and they see that they are kind of held back and constrained by the doctors (Academic tutor, 23). 
Nonetheless, these power struggles and dominant interests between participants and the medical profession did not represent the whole picture; competitive struggles for resources and power games also existed between the various allied health, midwifery and nursing professions represented at the Faculty of Health Sciences itself and this will be discussed in the next theme.

Hegemonies and territoriality at the faculty

I think what's happening is a power struggle between each and every department, which shouldn't be (Academic tutor, 3).

As exemplified by the above quote, this theme centred on issues related to interprofessional rivalry and conflict within the Faculty of Health Sciences itself and the implications of these power struggles for the development of IPE. Academic 3 talked of living with such conflict and actions motivated to protect positions of influence over the past 'twenty years':

I don't think any allied health care professional who's working here should have a right to stop you from developing your course; something which unfortunately has been happening since Day One I was here, and that is now twenty years (Academic tutor, 3).

Academic 1 also experienced interprofessional conflict, accounting for it as perhaps arising from some professions experiencing a sense of threat:

You might actually find that your plans are being hindered by other professions. I think that they're the professions who maybe feel threatened about what you are proposing to do (Academic tutor, 1).

And Academic 8 had similar views, suggesting that this sense of threat is all pervasive at the Faculty:

I mean the professions themselves - are we looking at each other as threats? I mean yes, I do feel that at this point in time, inside this Faculty, everybody feels threatened by other departments. That is how I feel (Academic tutor, 8).

And this sense of threat, participants suggested, can lead to staunch defensiveness that can only hinder IPE:

That change will take even longer in this area because the attitude I see right now in the health professions is we are too much defensive towards our own professions (Academic tutor, 51).

Competitiveness inherent in private practice beyond the Faculty, some participants suggested, may be one of the causes of defensiveness, territoriality and conflicts within the Faculty. In other words, as Academic 3 demonstrated, some professions, may be wary of sharing knowledge with another profession during IPE for fear that such knowledge could be used by that profession in private practice, thereby reducing the latter's need to refer patients to their profession, and ultimately, a reduction in referrals translating into a reduction in earnings:

I do not want to show another professional how I do my thing because otherwise when he goes to [into] private practice he may use it. I honestly think that private practice is a big barrier - we are afraid to refer a patient because we might lose them (Academic tutor, 3). 
Academic 50 pointed to a dilemma in reconciling sharing of knowledge during IPE, with maintaining the boundaries that define and delineate individual professional territories:

People want their boundaries. It's true no man is an island, but we need to have our boundaries, and there are boundaries which sometimes I might not want you to cross, you know, and when you have this openness, this interprofessional education,

sometimes those boundaries have to be crossed, by default (Academic tutor, 50).

Participants alluded to professional territories and boundaries in terms of both physical and conceptual 'spaces.' Academic 41 focused on the intangible or conceptual 'spaces' where boundaries are far more difficult to recognise and maintain and wherein IPE would pose profound challenge:

I, as a lecturer, when I'm facing a multi audience, what is my position? Where am I going to stop? What am I going to say? Am I going to cover everything, or am I still going to hold back some information to tell it to my group only (Academic tutor, 41)?

Discussions about professional territories and boundaries brought to the fore the question of student awareness and the acquisition of professional identity. An academic, who had referred to a need for strict boundaries in terms of physical space, continued the conversation in terms of a need for fostering in students a clear and definitive sense of their individual professional identities, suggesting that failure on the part of students to attain this strong sense of identity would signify that 'there is a problem':'

We are very careful to be specific in choosing subjects and choosing ways of delivering information that is completely identifiable with the definition of (profession) $\mathrm{X}$. Now, so when a student qualifies he feels, immediately feels, that he's (profession) $\mathrm{X}$ and not something else - if the student doesn't feel that way then there is a problem (Academic tutor 46).

It was perceived that the varying strengths of students' sense of professional identity could impact on the quality and outcome of their interactions in an IPE setting, almost depicting a 'survival of the fittest' scenario should an IPE initiative be implemented:

But we should remember that some professions always have had more prominence than others, so when they're in their first and second year if you put them together, some professions might be so strong with their identity ... it might dishearten the professions who are younger maybe, less established (Academic tutor, 16).

\section{Realities of teamwork}

Although participants placed high value on the concept of teams and agreed that effective teamwork would be a necessary cornerstone for any potential IPE initiative, the reality of everyday practice was experienced differently; overwhelming, they expressed concerns about a lack of collaboration both within the Faculty of Health Sciences as well as between the Faculty and across most of the health services.

Participants suggested that it would be 'useless' to expose students to IPE at the Faculty when, in their clinical placements, they would observe and experience practices that run counter to the development of teamwork and interprofessional collaboration:

So our students will go out into clinical practice and in clinical practice this philosophy does not exist, although we talk about interdisciplinarity, everyone is in his silo, so 
they go out, and they come back and say 'listen, the reality out there is a bit different' (Academic tutor, 18).

And the newly qualified health professionals spoke of witnessing lack of coordination between professionals in the practice environment.

It is lacking, especially when a patient is discharged, discharge planning is either absent or very poor in the medical wards. Liaison between the professionals is not very good (Newly Qualified Health Professional, 6).

Key informants pointed to such poor communication systems and structures in the provision of service as the outcome of a vicious cycle of cause and effect in terms of the relationship between the health education and the health service:

What one sees as silos within an academic setting then obviously develops into an even bigger and more serious problem within a service delivery setting (Key Informant).

And unfortunately, now we are feeling the effects within the service provision side of things, the effects of years of noncollaboration at the University (Key Informant).

While participant discussions at this level focused on the lack of interprofessional collaboration in the immediate education and practice settings and the ultimate implications in terms of patient care, some participants also expressed concern about the lack of communication between policy decision makers and academia:

But a big driver could be or should be the Department of Health. If they tell us the policy in which they would like the Health Service to go into, then maybe it could be a driving force for our curriculum; so if they tell us that they would like to go into primary health care in a big way or preventative medicine, then we will start taking our course in that direction (Academic tutor, 27).

This example of poor collaboration, provided insight into potential serious implications for the education and health sectors, and for the economy, when a 'silo' approach becomes so entrenched that educators and policy-makers can become so far removed from each other as to be almost operating as discrete rather than interrelated entities, and, indeed, a key informant deemed this to be the case:

We're still very much territorial in our approach, both Health and the University, so what is mine is mine, what is yours is yours, and if we agree, we agree, if we don't agree, we don't agree (Key Informant).

This lack of coherence and alignment between the local health authorities and the University suggests competing power and value systems between stakeholders; a serious departure from WHO guidelines on IPE which advocates seamless mechanisms between the health and education systems (WHO 2010).

\section{Discussion}

The findings above highlighted major concerns in relation to the interrelated complex issues of hegemonies, rivalries, professional territorialities, power, conflict and the acquisition of professional identity. At this stage, we engaged in what Simons refers to as 'dancing with the data which is an 'interpretative form of thematic analysis that gains depth, insight, and holistic understanding' (Simons 2009, 140) raising our awareness to the various contexts from which participants' discourses emerged. This was a process of looking beyond and transcending the tangible facts emanating from the findings so as to engage in higher order 
reconceptualisation. Bourdieu's theory of society and social practices was one of the theoretical lenses which we deemed particularly suited to consider and interpret the above findings serving us well to understand and demystify the perceptible power structures and power struggles.

\section{Relevance of Bourdieu's perspectives to the findings}

The findings suggested a continuous interplay between capital and habitus within a field of force. Power seemed to be culturally and symbolically created and constantly re-enacted through the interplay of agency and structure (Bourdieu and Wacquant 1992). Studying the relations between the players in the field was key to understand what was happening. Each participant's relative attributes depended on his or her position in the field, that is, the position, of that particular profession within the hierarchy of the other professions. The participants in this study, who came from a range of health professions (other than medicine) possessed different qualifications and competencies thus having different capital (social, cultural and economic) simultaneously operating at various levels and at different times. This capital was drawn upon or contributed to the professions entering the field and operating within the field. For example, the capital and habitus of nurses, midwives and allied health professionals differed from the capital and habitus of the medical doctor suggesting motives for the strong medical dominance experienced by participants and the lack of teamwork in clinical practice. Furthermore, the capital and habitus of nurses, midwives and allied health professionals also differed from each other implying that the excess of capital perceived by some professions was reflected in those same professions' eagerness to dominate other professions whom they recognised as potential subordinate rivals; akin to an implicit hierarchical pecking order where some professions were (or felt) more equal than others. Professions on the other hand who perceived themselves as having a lack of capital lamented, but still seemed to accept their positions as the dominated or 'threatened' professions. This was particularly seen in the theme 'hegemonies and territoriality at the faculty'.

The field of power within the Faculty of Health Sciences, the wider university and the health sector was a contested one between academics, health professionals and administrators who competed for personal and collective influence and dominance. These stakeholders seemed to struggle within a field saturated with vested interests. Participants noted that the abundance of one kind of capital accumulated by dominant stakeholders somehow seemed to pave the way for others kinds of capital. The medical model was undeniably the overriding model of local health care practices being reproduced on a daily basis in the various contexts: hospitals, within the Health administrative sector and in the community at large. Its' dominant forms of capital (symbolic, social, economic and cultural) ellicited symbols of prestige such as specialised knowledge, particular dress codes/stethoscopes within clinical environments, and authority and reputation elsewhere.

In addition to the access of capital by the medical profession, the idea of capital as forms of valued resources was reflected by participants coming from the other health professions when they tended to assume relatively dominant or subordinate positions, according to how much legitimate capital they (or the profession they pertained to) perceived could access. From a Bourdieusian perspective the different health professions possessed and mobilised 
different forms of capital that afforded them greater status, knowledge, skills and expertise. In addition, these professions were deeply rooted in different traditions, each with its own level and form of capital, and the ability to mobilise additional capital so as to assert their position in the social order. For example, in the process of professionalisation, the professions (each with its own habitus) commented on how they strived to acquire, develop and improve their access to institutionalised cultural capital through improvements in their body of 'scientific' knowledge, technological developments, visibility to the public and introducing new areas of expertise. Hence, it is hardly surprising that participants were suspicious that IPE might threaten their whole professional ethos spiralling into dilution and/or jeopardy of this capital.

Almås (2007) notes that the cultural capital of a profession varied according to the characteristics and pedagogic approaches of that profession, reproduced and transferred from one generation to the another. And as students are socialised within such norms, such differences influenced the variation of how students valued interprofessional working. Although our study was not a cross professional study, we observed that participants coming from the seemingly dominant professions were vociferous in their ambivalence towards IPE, whereas other professions coming from less dominant professions showed neutral attitudes. Another example was private practice, by which professions convert their institutionalised cultural capital (recognition, academic credentials and qualifications and which must be understood from a historical, social and cultural perspective) to economic capital. The struggle to establish, maintain and perpetuate this economic capital was evident when participants suggested that private practice would challenge the notion of collaborative practices because professions would be reluctant to refer patients to another profession fearing not only loss of economic but also symbolic and social capital ${ }^{5}$ : a phenomenon which could be more accentuated in Malta due to the microstate syndrome (Sultana and Baldacchino 1994). This suggests that in addition to individual attributes, capital is a key tenant in dictating positions within the field making collaborative practices more challenging.

During the analysis of participant's discourses, the question of professional identity emerged as a recurring theme and academics were concerned that IPE could dilute the acquisition of professional identity at the level of the student and/or practitioner. They spoke about the strategic importance of shaping their students in such a way as to embody the rules, beliefs and habits of their profession, echoing Wackerhausen's (2009) perspective on micro level identity as necessitating the practitioner to 'be one of our kind' and 'to stay one our kind ever after' (461). This is directly related to the concept of habitus which embodies the way in which individuals become themselves through a system of dispositions, attitudes and ideologies (Bourdieu and Wacquant 1992). In the light of habitus being a permeable concept that can be moulded to form human behaviour (Navarro 2006) and it being a combination of a person's ingrained identity and a more transient (but likewise deep-seated) identity representing skills and dispositions that are acquired from life experiences, (for example being a student, a parent or a health professional) (Meisenhelder 1997), it seems reasonable to suggest that this formative component of professional habitus which particularly develops through processes of socialisation (Navarro 2006), can be compared with professional identity; this in turn is inextricability linked to the complex process of professional socialisation (Clark 2014). 
Doxa too was relevant in that although all participants had a common health care background, their daily practices were informed by differing core value systems. For example, it was noted that participants pertaining to those professions whose value system was geared more towards a biomedical orientation (thus possibly implying less collaborative efforts) rather than a patient oriented one (thus possibly necessitating less collaborative efforts) were more resistive towards IPE. Similarly, the doxa of medical, nursing and allied health professionals might have indeed been the well-being of the patient, however whereas doctors espoused to the medical model of disability, many of the profession in this case study subscribed to the social model of disability. Different professions could have then pursued strategies and made use of their capital to employ and/or impose rules that would favour them the most. And this was amply evident in the findings, for example when participants referred to a 'tug-of-war between extremes', a particular philosophy espoused in class being overturned in practice or the lack of overt collaboration between professions.

\section{Recommendations/implications}

In Baldwin's (D’Avray 2007) words,

the liberating philosophies and practices of egalitarianism, openness, empowerment and cooperation, implicit in both IPE and interprofessional practice, are a direct challenge to the existing establishment because they threaten to level the playing field and to empower other health professionals (13).

Examining the findings from a Bourdiesian perspective provided a critical lens to examine power interplay, dominant interests and lack of collaboration emerging as barriers to a possible IPE initiative. Whilst Bourdieu acknowledged that covert competitive strategies to advance one's position and legitimise power are a reality of social groupings (Bourdieu 1984), understanding motives for power dynamics and the contestation for resources unearths some of the reasons for the terse interprofessional relations emerging from this case study. Bourdieu advocates for reflexive analysis, reflecting on and critiquing power relations and dynamics which could potentially be useful in changing the rules of the game. Furthermore, the comparison made earlier suggesting that the transient or formative component of habitus which particularly develops through processes of socialisation (Navarro 2006) can be compared with professional identity, which in turn is inextricability linked to the complex process of professional socialisation (Clark 2014), could have a number of implications for IPE. The idea that habitus is capable of change, suggests that identifying those periods when habitus is possibly more susceptible to external influences could be significant for the timing of an IPE initiative. Applying a Bourdieusain's lens to this study's findings also supports Hean et al.'s (2012) pragmatic propositions for utilising the idea of social capital so as consider optimum size and level of representation of interprofessional learning groups.

\section{Conclusion}

This case study has sought to explore participants' understandings and perceptions of IPE including the possibility of developing and sustaining an undergraduate IPE initiative at the Faculty of Health Sciences, University of Malta. The findings reported here have raised concerns about the notion of power and conflict present in a potential IPE initiative and suggest that IPE would face symbolic barriers of strong medical dominance, hegemonies, 
territorialities and lack of collaboration at all levels. The originality of this study lies in examination of these findings from a Bourdieusian perspective reflecting Beattie's (1995) anthropological metaphor of 'tribalism' for health professions in that:

Health is and will remain a vigorously 'contested concept', there will continue to be a plurality of competing views and values related to health, and that complexity and contradiction will be a constant challenge to all efforts at organisational development and social planning for health (Beattie 1995, 6).

Fuzzy generalisations (Bassey 2001) from this work can be used as 'sound bites' by policy makers. Whilst an equilibrium of power is unattainable from a Bourdieusian perspective, the challenge for all professions and all stakeholders involved in the development of IPE, is to be cognisant of field dynamics so as to be in a better position to demystify and possibly reduce the existence of these embedded hierarchies, conflicts and power struggles across health professions and health systems. Failure to do so would be the entrenchment and reproduction of existing hierarchical structures undermining the very core values of IPE.

\section{Limitations of the study}

This study focused on a potential IPE initiative at the Faculty of Health Sciences, as opposed to including other health and social care professionals outside the Faculty. This was an artificial boundary for IPE; however, to have explored perceptions from other faculties might have compromised the depth of the study, as well as bringing to the fore a number of variables between faculties which would have been difficult to reconcile during data analysis.

Notes

1. Whilst a review of these theories is beyond the scope of this paper, the interested reader isinvited to look at Adams et al. (2006), Barr et al. (2005); Barr 2013, Hean, Craddock, and O'Halloran (2009), Hean et al. (2012), Reeves et al. (2007) and Reeves and Hean (2013) for detailed accounts.

2. Professional education for medicine, dentistry, pharmacy and social work is undertaken byother faculties.

3. These participant academics had a practising health professional background and would havemoved to academia over the years.

4. Sixty-seven letters were send to all eligible newly qualified professionals however only eightpositive responses were received. On the day of the focus group, 2 participants cancelled their participation due to unforeseen circumstances.

5. Prestige, titles, reputations and knowing and being known to the right people could be realconcerns for inhabitants living in a small geographical island, such as Malta.

\section{Disclosure statement}

No potential conflict of interest was reported by the authors. 


\section{Notes on contributors}

Dr. Marjorie Bonello (Primary author): Lecturer, Faculty of Health Sciences, University of Malta. Her main interests are interprofessional education theory, policy and practice, education in practice across the health professions and qualitative methodologies. She is also interested in the potential impact of national culture on innovation in health professional education, especially in European mini-states and other nations.

Dr.Jon Wright: Principal Lecturer, School of Health Sciences, University of Brighton.

Dr. Jane Morris: Deputy Head of School of Health Sciences, School of Health Sciences, University of Brighton, UK; Chair, National Association of Educators in Practice (NAEP).

Professor Gaynor Sadlo: Professor of Occupational Science (retired), School of Health Sciences, University of Brighton, UK.

References

Adams, K., S. Hean, P. Sturgis, and J. Macleod Clark. 2006. "Investigating the Factors Influencing Professional Identity of First-year Health and Social Care Students." Learning in Health and Social Care 5 (2): 55-68.

Almås, S. H. 2007. "Interprofessional Education: An Analysis of the introduction of a Common Core in Curricula for Selected Health Professions." Doctoral dissertation. https://bora.uib.no/ handle/1956/2563.

Barr, H. 2013. “Toward a Theoretical Framework for Interprofessional Education.” Journal of Interprofessional Care 27 (1): 4-9.

Barr, H., I. Koppel, S. Reeves, M. Hammick, and D. Freeth. 2005. Effective Interprofessional Education: Argument, Assumption, and Evidence. Oxford, UK: WileyBlackwell.

Bassey, M. 2001. "A Solution to the Problem of Generalisation in Educational Research: Fuzzy Prediction.” Oxford Review of Education 27 (1): 5-22.

Beattie, A. 1995. "War and Peace among the Health Tribes." In Interprofessional Relations in Health Care, edited by K. Soothill, L. Mackay and C. Webb, 11-30. London: Arnold.

Bourdieu, P. 1984. Distinction: A Social Critique of the Judgement of Taste. Cambridge, MA: Harvard University Press.

Bourdieu, P. 1986. "The Forms of Capital." In Handbook of Theory and Research for the Sociology of Education, edited by John G. Richardson, 241-258. New York: Greenwood.

Bourdieu, P. 1989. "Social Space and Symbolic Power." Sociological Theory 7 (1): 14-25.

Bourdieu, P. 1990. The Logic of Practice. Stanford, CA: Stanford University Press.

Bourdieu, P., and L. J. Wacquant. 1992. An Invitation to Reflexive Sociology. Chicago: University of Chicago Press.

Chesters, J., and M. Burley. 2011. "Beyond Professional Conflict: Cultural and Structural Barriers to Interprofessional Health Care Teams.” In Sociology of Interprofessional Health Care Practice, edited by S. Kitto, J. Chesters, J. Thistlethwaite and S. Reeves, 105-118. New York: Nova Science Publishers.

Clark, P. G. 2014. "Narrative in Interprofessional Education and Practice: Implications for Professional Identity, Provider-patient Communication and Teamwork." Journal of Interprofessional Care 28 (1): 34-39.

Cooper, H., S. Braye, and R. Geyer. 2004. "Complexity and Interprofessional Education." Learning in Health and Social Care 3 (4): 179-189.

D’Avray, L. 2007. "Interview with DeWitt C. Baldwin Jr.” Journal of Interprofessional Care 21 (S1): 4-22.

Freidson, E. 1988a. Profession of Medicine; a Study of the Sociology of Applied Knowledge. Chicago: University of Chicago Press. 
Freidson, E. 1988b. Professional Powers: A Study of the Institutionalization of Formal Knowledge. Chicago: University of Chicago Press.

Freidson, E. 1994. Professionalism Reborn: Theory, Prophecy, and Policy. Chicago: University of Chicago Press.

Frenk, J., Z. A. Bhutta, L. C. H. Chen, J. Cohen, N. Crisp, T. Evans, and P. Kelley. 2010. "Health Professionals for a New Century: Transforming Education to Strengthen Health Systems in an Interdependent World." The Lancet 376 (9756): 1923-1958.

Hall, P., and L. Weaver. 2001. "Interdisciplinary Education and Teamwork: A Long and Winding Road." Medical Education 35 (9): 867-875.

Harris, B. A. 2006. "Pauline Cerasoli Lecture 2006. Interdisciplinary Education: What, Why, and When?" Journal of Physical Therapy Education 20 (2): 3-8.

Hean, S., D. Craddock, M. Hammick, and M. Hammick. 2012. "Theoretical Insights Into Interprofessional Education: AMEE Guide No. 62." Medical Teacher 34 (2): 78-101.

Hean, S., D. Craddock, and C. O'Halloran. 2009. "Learning Theories and Interprofessional Education: A User's Guide." Learning in Health and Social Care 8 (4): 250-262. Jenkins, R. 2014. Pierre Bourdieu. Abingdon: Routledge.

Kamberelis, G., and G. Dimitriadis. 2005. "Focus Groups: Strategic Articulations of Pedagogy, Politics, and Inquiry." The Sage Handbook of Qualitative Research 3: 887907.

Khalili, H., J. Hall, and S. DeLuca. 2014. "Historical Analysis of Professionalism in Western Societies: Implications for Interprofessional Education and Collaborative Practice." Journal of Interprofessional Care 28 (2): 92-97.

Larson, M. S. 1977. The Rise of Professionalism: A Sociological Analysis. Vol. 233. Berkeley: University of California Press.

Lincoln, Y. S., and E. G. Guba. 1985. Naturalistic Inquiry. Newbury Park, CA: Sage Publications.

Lynam, M. J., A. J. Browne, S. Reimer Kirkham, and J. M. Anderson. 2007. "Re-Thinking the Complexities of 'Culture': What Might We Learn from Bourdieu?" Nursing Inquiry 14 (1): 23-34.

Meisenhelder, T. 1997. "Pierre Bourdieu and the Call for a Reflexive Sociology." Current Perspectives in Social Theory 17: 159-186.

Ministry for Health. 2014. A National Health Systems Strategy for Malta (NHSS): 2014 2020 Securing Our Health System for Future Generations. Malta: Ministry for Health.

Navarro, Z. 2006. "In Search of a Cultural Interpretation of Power: The Contribution of Pierre Bourdieu." IDS Bulletin 37 (6): 11-22.

Noor, K. 2008. "Case Study: A Strategic Research Methodology.” American Journal of Applied Science 5 (11): 1602-1604.

Paradis, E., and S. Reeves. 2013. "Key Trends in Interprofessional Research: A Macrosociological Analysis from 1970 to 2010.” Journal of Interprofessional Care 27 (2): 113-122.

Reeves, S., S. Fletcher, H. Barr, I. Birch, S. Boet, N. Davies, and S. Kitto. 2016. "A BEME Systematic Review of the Effects of Interprofessional Education: BEME Guide No. 39." Medical Teacher 38 (7): 656-668.

Reeves, S., and S. Hean. 2013. "Why We Need Theory to Help Us Better Understand the Nature of Interprofessional Education, Practice and Care." Journal of Interprofessional Care 27 (1): 1-3.

Reeves, S., K. MacMillan, and M. Van Soeren. 2010. "Leadership of Interprofessional Health and Social Care Teams: A Socio-historical Analysis.” Journal of Nursing Management 18 (3): 258- 264.

Reeves, S., E. Suter, J. Goldman, T. Martimianakis, C. Chatalalsingh, and D. Dematteo. 2007. A 
Scoping Review to Identify Organizational and Education Theories Relevant for Interprofessional Practice and Education. Calgary Health Region \& QUIPPED — Queen's University Inter-Professional Patient-Centred Education Direction.

https://www.researchgate.

net/profile/Scott_Reeves/publication/237784416_A_scoping_review_to_identify_organiz ational_

and_education_theories_relevant_for_interprofessional_practice_and_education/links/0c9 6053 96f373e1dac000000.pdf.

Ritchie, J., and L. Spencer. 1994. "Qualitative Data Analysis for Applied Policy Research.” In Analysing Qualitative Data, edited by A. Bryman and R. G. Burges, 173-194. London: Routledge.

Schinkel, W., and M. Noordegraaf. 2011. "Professionalism as Symbolic Capital: Materials for a Bourdieusian Theory of Professionalism." Comparative Sociology 10 (1): 67-96.

Simons, H. 2009. Case Study Research in Practice. London: Sage Publications.

Stake, R. E. 1995. The art of Case Study Research. Thousand Oaks, CA: Sage Publications.

Sultana, R., and G. Baldacchino. 1994. Maltese Society: A Sociological Inquiry. Malta: Mireva Publications.

Wackerhausen, S. 2009. "Collaboration, Professional Identity and Reflection Across Boundaries.” Journal of Interprofessional Care 23 (5): 455-473.

World Health Organization. 2010. Framework for Action on Interprofessional Education and Collaborative Practice. Geneva: World Health Organisation.

World Health Organization. 2013. Transforming and Scaling up Health Professionals' Education and Training: World Health Organization Guidelines 2013. Geneva: World Health Organization. 